\title{
A ORDEM DOS CLÍTICOS PRONOMINAIS EM COMPLEXOS VERBAIS: AS NORMAS DE USO EM CARTAS DE LEITOR
}

\author{
THE ORDER OF PRONOMINAL CLITICS IN COMPLEX VERBALS: NORMS OF USE IN READERLETTERS \\ EL ORDEN DE LOS CLÍTICOS PRONOMINALES EN COMPLEJOS VERBALES: LAS NORMAS DE USO EN \\ CARTAS DE LECTOR
}

Márcia Saldanha Peterson Silvia Rodrigues Vieira ${ }^{*}$

Universidade Federal do Rio de Janeiro - UFRJ, Rio de Janeiro, BR

\begin{abstract}
RESUMO: O artigo focaliza o tema da colocação pronominal em construções com mais de uma forma verbal, com base no levantamento - realizado em Peterson (2010) - das ocorrências em cartas de leitor de três jornais veiculados na cidade do Rio de Janeiro. Tendo analisado os dados de acordo com os pressupostos da Sociolinguística Laboviana, a pesquisa, embora demonstre que o gênero textual carta de leitor registra, de modo geral, a variante intra-complexo verbal sem hífen (pode me dizer), produtiva e natural no Português do Brasil, evidencia que os jornais apresentam comportamento diferenciado quanto à proximidade/ distância em relação às normas idealizadas por manuais prescritivos. As diferenças ocorrem não só em função de motivações linguísticas, mas, sobretudo devido a motivações extralinguísticas, relacionadas ao perfil do veículo de comunicação.
\end{abstract}

PALAVRAS-CHAVE: variação; ordem; clític.

ABSTRACT: This paper focuses on pronominal order in verbal periphrases, taking into consideration data from a research developed by Peterson (2010) in which clitic pronouns produced by newspaper readers from Rio de Janeiro city have been analysed. Developed within the framework of Labovian Sociolinguistics, the study demonstrates that although the readers' correspondences present the alternant form $\mathrm{V} 1 \mathrm{cl} \mathrm{V} 2$ (pode me dizer), highly productive and natural in Brazilian Portuguese, different uses can be observed in relation to proximity or distance to idealized linguistic norms which are proposed by prescriptive manuals. Not only linguistic motivations, but also extralinguistic restrictions (regarding mainly newspapers' characteristics) have been associated to the pronominal order.

KEYWORDS: variation; order; clitic.

RESUMEN: El artículo se centra en el tema de la colocación pronominal en construcciones con más de una forma verbal, con base en el levantamiento - realizado en Peterson (2010) - de las ocurrencias en cartas de lector de tres periódicos de la ciudad de Rio de Janeiro. Habiendo analizado los datos de acuerdo con los supuestos de la Sociolingüística Laboviana, la investigación, aunque demuestre que el género textual carta de lector registra, de modo general, la variante intracomplejo verbal sin guión (pode me dizer), productiva y natural en la variante brasileña del portugués, evidencia que los periódicos presentan un comportamiento diferenciado con respecto a la cercanía / lejanía con relación a las normas idealizadas por los manuales prescriptivos. Las diferencias ocurren no solamente en función de motivaciones lingüísticas, sino sobre todo debido a motivaciones extralingüísticas, relacionadas con el perfil del vehículo de comunicación.

PALABRAS-CLAVE: variação; orden; clítico.

\section{DELIMITANDO OS PROPÓSITOS DESTE ARTIGO}

Embora diversos estudos tenham sido dedicados ao fenômeno da colocação pronominal, acredita-se haver, ainda, muito a investigar sobre o assunto, especialmente no que tange ao conhecimento das normas reais que orientam a ordem dos pronomes átonos nas construções com mais de uma forma verbal (complexos verbais) na modalidade escrita do Português do Brasil. A fim de detectar o que seria o padrão culto escrito, tem-se assumido, nos estudos linguísticos, que o domínio jornalístico - considerando-se, especialmente, os gêneros textuais que representam o veículo em que se encontram, como, por exemplo, os editoriais, as notícias, as reportagens - constitui espaço apropriado para observar a(s) norma(s) prestigiada(s) socialmente e que estariam em uso.

No caso do presente artigo, para a investigação da ordem dos pronomes átonos em complexos verbais, elegeu-se, da ampla variedade de gêneros textuais que constituem o domínio jornalístico, as cartas de leitor, objeto de estudo específico do estudo desenvolvido em Peterson (2010), de cujos resultados partem as reflexões ora propostas. Sabe-se que as cartas de leitores assumem caracterização bastante particular, tendo 
em vista que representam a palavra dos consumidores do jornal que constituem o público-alvo do veículo em foco, como se poderá observar ao longo do artigo.

Interessa investigar, em especial, a hipótese de que, embora as cartas de leitores apresentem características comuns, próprias do gênero textual, o perfil do veículo de comunicação exerceria efeito relevante no controle da variação da ordem dos clíticos pronominais em complexos verbais. Isto porque, tendo o tema forte vinculação com a norma de prestígio idealizada para a modalidade escrita, a maior ou menor aproximação a essa norma daria feições próprias a cada tipo de veículo. Por hipótese, jornais direcionados às classes mais abastadas socioeconomicamente (supostamente mais escolarizadas) tenderiam a ser mais rigorosos com o que se idealiza como padrão culto escrito, enquanto os direcionados às classes menos abastadas (supostamente menos escolarizadas) teriam menor compromisso em reproduzir o que se supõe ser, no Português do Brasil, o padrão culto idealizado pelos meios escolarizados.

Em linhas gerais, a presente pesquisa pretende: (i) determinar, em termos variacionistas labovianos, o padrão de colocação pronominal e suas motivações estruturais e extralinguísticas nas cartas analisadas; (ii) verificar se há um padrão típico do gênero carta de leitor no que se refere à ordem dos pronomes clíticos nos complexos verbais; e (iii) avaliar, no que tange ao fenômeno da colocação pronominal, a proximidade/distância das normas de uso em relação às normas idealizadas em compêndios gramaticais prescritivos (cf., por ex., CUNHA; CINTRA, 2001). Para tanto, o estudo considera textos extraídos de três veículos de comunicação cariocas, o Jornal O Globo, o Extra e o Meia Hora.

\section{FUNDAMENTOS TEÓRICOS E PROCEDIMENTOS METODOLÓGICOS}

Compreendem-se como complexo verbal, neste estudo, as estruturas constituídas de duas ou mais formas verbais que mantêm entre si algum grau de integração sintático-semântica e que podem admitir, em maior ou menor grau, a mobilidade dos clíticos pronominais. Trata-se, além da estrutura de voz passiva analítica, de construções temporais, aspectuais, modais, volitivas/declarativas ${ }^{1}$.

Como variável dependente, de caráter eneário, tem-se, ao menos como possibilidade, a ordem dos pronomes nas lexias verbais complexas com a seguinte configuração: pré-complexo verbal (se pode fazer), intracomplexo verbal com ligação explícita a V1, por meio do hífen (pode-se fazer) ou sem tal ligação (pode se fazer) e pós-complexo verbal (pode fazer-se). ${ }^{2}$

Para a investigação da influência dos fatores linguísticos e extralinguísticos que motivam o uso das variantes pré-complexo verbal, pós-complexo verbal ou intra-complexo verbal (com hífen e sem hífen), o estudo fundamenta-se em pressupostos teórico-metodológicos da Sociolinguística Variacionista de orientação laboviana (WEINREICH; LABOV; HERZOG, 1968; LABOV, 1972, 1994).

Os dados da pesquisa foram selecionados de cartas de leitores brasileiros coletados nos jornais cariocas $O$ Globo, Extra e Meia Hora publicados em 2008/2009. Esses veículos foram escolhidos em função de serem direcionados, respectivamente, às classes consideradas socioeconomicamente muito favorecidas, medianamente favorecidas e pouco favorecidas. Respaldam essa escolha não só a observação da natureza e da abordagem dos temas focalizados, mas também o preço do jornal.

A amostra que serve de base à análise é constituída de todas as ocorrências de clíticos pronominais em complexos verbais encontrados em 600 cartas de cada jornal, totalizando 1.800 textos. Para o tratamento dos dados, utilizou-se a ferramenta estatística do pacote de programas computacional Goldvarb-X. Os resultados apresentados neste trabalho referem-se a índices absolutos e percentuais, e não a pesos relativos, tendo em vista a baixa produtividade dos complexos verbais - especialmente das estruturas com particípio e gerúndio, mas também no caso dos infinitivos - e o fato de a variável ser eneária.

\footnotetext{
${ }^{1}$ Estruturas com verbos causativos/ sensitivos, as quais apresentam baixo grau de auxiliaridade, não são aqui contempladas, sobretudo por nem sempre admitirem a mobilidade do clítico em relação às formas verbais da perífrase.

2 As variantes internas ao complexo costumam ser identificadas como concretizações da ênclise ao verbo auxiliar (V1) e da próclise ao verbo principal (V2). Não se trata, aqui, de próclise e ênclise em termos fonético-fonológicos, já que não se pode atestar a ligação fonética do clítico com base exclusivamente na modalidade escrita.
} 


\section{A COLOCAÇÃO PRONOMINAL EM COMPLEXOS VERBAIS NAS CARTAS DE LEITORES}

Inicialmente, cabe destacar que a quantidade de ocorrências de clíticos em complexos verbais, em geral, foi menor do que a esperada: coletando-se as ocorrências nos 600 textos de cada jornal, somente 132 dados de pronomes átonos em estruturas com mais de uma forma verbal foram encontrados. Essa baixa produtividade da construção em foco pode indicar que a própria estrutura verbal complexa não seja muito comum em cartas de leitor, hipótese que suscitaria uma investigação particular.

É relevante salientar, ainda, a diferença considerável do número total de dados encontrados em cada veículo: no jornal $O$ Globo, 93 ocorrências; no Extra, 34; e no Meia Hora, somente 5. Pode-se pressupor que essa discrepância esteja relacionada não só ao tamanho dos textos (que são menores no Meia Hora), mas também ao perfil das cartas presentes nesses jornais e ao próprio perfil dos veículos quanto às normas linguísticas concretizadas, o que será detalhado, aqui, quanto ao fenômeno da ordem dos clíticos pronominais.

Deve-se atentar, ainda, para a considerável diferença do número de complexos em relação à forma do verbo principal - no gerúndio, no particípio ou no infinitivo. Há 103 ocorrências do clítico em construções com a forma do verbo principal infinitiva - as mais produtivas -, apenas 16 ocorrências com verbo principal no gerúndio, e 13 no particípio.

Quanto ao perfil dos veículos, verificam-se diferenças gerais entre os jornais considerados na pesquisa, que aqui se detalham. $O$ Globo trata de diversos assuntos, tais como: economia, saúde, educação, esporte, política; apresenta textos de diversos gêneros textuais, como cartas de leitor, anúncios, editoriais, notícias, crônicas. O jornal Meia Hora exibe menos informações, e, em geral, além de anúncios, apresenta diversas notícias que se concentram nos temas de violência, criminalidade e esportes. O Extra, por sua vez, pode ser localizado na linha de um continuum - quanto à variedade de temas e gêneros textuais, e à forma de abordálos -, entre os outros dois jornais. O Extra trata de diversos assuntos; suas notícias exibem informações não tão restritas como as do Meia hora, mas não tão amplas quanto as de $O$ Globo (em alguns casos, ignoram, por exemplo, temas de âmbito nacional, priorizados em $O$ Globo); quanto aos gêneros textuais, o Extra não apresenta, por exemplo, a crônica, e priori-za notícias e anúncios, em geral.

No que se refere ao perfil das cartas de leitor, nota-se, também, que as do jornal $O$ Globo têm algumas características distintas das apresentadas nas cartas dos jornais Extra e Meia Hora. A diferença revela-se, de início, no título das seções referentes às cartas - Cartas de Leitor, no jornal O Globo; Carta Branca, no Extra; e Voz do Povo, no Meia Hora. Nota-se que os títulos das cartas do Extra e do Meia Hora sugerem que o propósito dessas cartas possa ser distinto do propósito das cartas de $O$ Globo. No Jornal $O$ Globo - que publica 24 textos por dia, alguns referentes ao mesmo assunto -, as cartas são mais longas e mais direcionadas para críticas, de acordo com o interesse e a reflexão dos leitores acerca de temas da atualidade, vinculados a edições anteriores do jornal. No jornal Meia Hora - que publica somente oito cartas por dia -, os textos são mais curtos, direcionados para reclamações e denúncias de todos os tipos, e apresentam conteúdos de interesse popular mais imediato, como, por exemplo, a indignação pela queda de uma árvore, pela falta de luz, ônibus escasso. As cartas presentes no Extra - em torno de treze por dia - também são, em sua totalidade, voltadas para reclamações e dúvidas, mas há uma seção em que são emitidas opiniões a respeito de alguma questão levantada pelo jornal. Uma vez mais, percebe-se, num continuum entre os jornais, que, enquanto $O$ Globo figura, num extremo, com conteúdo de caráter mais reflexivo e avaliativo nas cartas, e o Meia Hora, em outro, com caráter menos reflexivo, o Extra mescla conteúdos mais populares e alguns mais críticos, em que o leitor teria "carta branca" para demonstrar seus anseios.

Com relação à linguagem utilizada nos jornais - numa observação superficial das estruturas e do vocabulário usados -, o jornal $O$ Globo parece fazer uso de uma linguagem mais voltada para o padrão culto idealizado na tradição gramatical para contextos formais, apresentando variedade linguística menos popular, períodos mais longos e vocabulário mais rebuscado (como se pode observar no fragmento "Este ano, praticamente o Congresso Nacional "trabalhou" somente para resolver as denúncias de vários escândalos que encheram a sua pauta. Somente o caso Sarney tomou mais de quatro meses de constantes sessões prenhes de acusações entre os senadores da casa"). No jornal Meia Hora, há aparentemente certo desapego ao que se costuma conceber idealmente como escrita culta padrão, de modo que as cartas, por exemplo, exibem períodos curtos e o vocabulário empregado aproxima-se por vezes do empregado em conversas pouco monitoradas (como se 
pode observar no fragmento "Basta uma chuvinha e a R. Dr. Augusto Figueiredo se torna o caos. A água suja alaga toda a via e invade nossas casas.") -, comportamento que faz supor que se priorizem, em tal veículo de comunicação, uma variedade linguística mais popular e um vocabulário mais próximo do que se costuma empregar na oralidade ou na escrita informais. O jornal Extra, por sua vez, parece fazer uso de expressões linguísticas não tão marcadas, nem como prototípicas da escrita/oralidade formal, nem como prototípicas da oralidade/escrita informal, uma espécie de meio-termo. Ao que parece, apresenta-se, no Extra, uma forma de expressão com certa neutralidade, que a aproxima, de um lado, do registro semiformal oral, e, de outro, de um padrão considerável aceitável também dentro da escrita semiformal.

\subsection{Distribuição dos dados pela variável dependente}

Observe-se, a seguir, a distribuição de dados pela variável dependente, considerando-se o total de ocorrências e cada forma do verbo principal (infinitivo, gerúndio, particípio), segundo Peterson (2010):

Tabela 1 - Distribuição dos dados da ordem dos clíticos em complexos verbais - geral e por forma do verbo principal (PETERSON, 2010):

\begin{tabular}{|c|c|c|c|c|c|}
\hline $\begin{array}{c}\text { Forma do verbo } \\
\text { principal }\end{array}$ & $\mathrm{cl} \mathrm{V1} \mathrm{V2}$ & $\mathrm{V} 1-\mathrm{cl} \mathrm{V} 2$ & $\mathrm{~V} 1 \mathrm{cl} \mathrm{V} 2$ & $\mathrm{~V} 1 \mathrm{~V} 2-\mathrm{cl}$ & Total \\
\hline Infinitivo & $21-21 \%$ & $6-6 \%$ & $56-54 \%$ & $20-19 \%$ & 103 \\
\hline Gerúndio & $3-19 \%$ & $1-6 \%$ & $12-75 \%$ & $0-0 \%$ & 16 \\
\hline Particípio & $4-31 \%$ & $2-15 \%$ & $7-53 \%$ & $0-0 \%$ & 13 \\
\hline Total & $28-21 \%$ & $9-7 \%$ & $75-57 \%$ & $20-15 \%$ & 132 \\
\hline
\end{tabular}

No que tange à colocação dos pronomes átonos, verifica-se que há a preferência, com todas as formas do verbo principal, pela posição intra-CV sem hífen, totalizando $57 \%$ de ocorrências. Houve somente nove ocorrências da variante intra-CV com hífen - seis delas com infinitivo, uma com gerúndio e duas com particípio -, totalizando $7 \%$ das ocorrências. A variante pré-CV foi concretizada em $21 \%$ das ocorrências e a variante pós-CV, que ocorreu apenas nas construções infinitivas, em $15 \%$ do total de dados.

A fim de ilustrar os fatores da regra variável, apresentam-se, a seguir, alguns exemplos extraídos do corpus, todos com construções infinitivas, a mais produtiva na amostra.

cl V1 V2 ou variante pré-complexo verbal (pré-CV)

(1) Essa turbulência tem mostrado que quem manda no mundo são os investidores especuladores e, portanto, não se pode esperar que tal idéia parta deles. (O Globo, 15/10/08)

V1-cl V2 ou variante intra-complexo verbal (intra-CV) - com hífen

(2) Todavia, deve-se analisar, cuidadosamente, se este tem condições gerais de ter a guarda. (O Globo, 17/03/09)

V1 cl V2 ou variante intra-complexo verbal (intra-CV) - sem hífen

(3) O ser humano, quando está sob o domínio da mídia, pode se sentir pressionado, sem privacidades e outras bobagens. (Extra, 11/04/09).

V1 V2 cl ou variante pós-complexo verbal (pós-CV)

(4) Quando fazem, os cidadãos vizinhos, se é que podemos chamá-los assim. (Extra, 09/04/09)

\subsection{Análise dos dados de acordo com a forma do verbo principal}

Dada a distribuição particular dos dados em cada tipo de complexo verbal, passa-se a apresentar os resultados por forma do verbo principal. 


\subsubsection{As variantes da ordem dos clíticos em complexos verbais com particípio}

Os 13 dados de clíticos em construções participiais registraram, em pouco mais da metade das ocorrências (7 em 13), o pronome átono no interior do complexo verbal sem hífen (tenho me sentido).

Em estrutura complexa de voz passiva, tal comportamento parece se modificar, passando a predominar a posição pré-complexo verbal (não lhe foi informado). Além disso, ocorreram apenas duas ocorrências da posição intra-CV com hífen, em contexto específico: ambas com a forma auxiliar no infinitivo, seguida de $o$ / lhe (tê-lo chamado). Não houve registros da variante pós-CV com particípio, resultado que está de acordo com o que recomenda a tradição gramatical.

O comportamento atestado nas ocorrências do corpus precisa ser verificado em maior quantidade de dados, a fim de permitir aferir as efetivas tendências das cartas de leitor no que se refere à colocação pronominal em complexos com particípio.

\subsubsection{As variantes da ordem dos clíticos em complexos verbais com gerúndio}

Das 16 ocorrências de clíticos em construções com verbo principal no gerúndio, 12 registraram o pronome na posição intra-CV sem hífen (estão me cobrando). Apenas três dados apresentaram o clítico na posição précomplexo verbal, dados em que se dá a presença de possível elemento proclisador e que contam com clíticos específicos pouco produtivos no $\mathrm{PB}$, como o acusativo de $3^{\mathrm{a}}$ pessoa (que o está influenciando). Em relação à variante intra-CV com hífen, houve somente uma realização do pronome átono, em construção indeterminadora (fica-se sabendo).

Notou-se, também, que a estrutura complexa formada por verbo estar + gerúndio foi a que mais apareceu no corpus e abrigou o clítico na posição intra-CV sem hífen, independentemente da presença de possível elemento proclisador.

Embora o número de dados tenha sido pequeno, pôde-se perceber que esse tipo de complexo não tende a acomodar o clítico na posição anterior ou posterior ao complexo verbal, mas, sim, na posição intra-CV sem hífen. As ocorrências das variantes pouco produtivas parecem estar vinculadas fundamentalmente à variável tipo de clítico, o que só poderá ser confirmado, efetivamente, com a ampliação do número de ocorrências em trabalho futuro.

\subsubsection{As variantes da ordem dos clíticos em complexos verbais com infinitivo}

Na subamostra com as construções verbais infinitivas, que conta com 103 ocorrências, foi possível verificar a variabilidade do fenômeno, tendo sido a variante intra-CV sem hífen (pode me dizer) a mais produtiva (54\%) também nesse contexto. A observação do comportamento dos dados em relação às variáveis independentes controladas permitiu verificar os contextos em que cada forma alternante se manifestou.

Dos grupos de fatores linguísticos, destaca-se, aqui, o comportamento dos dados em relação aos seguintes: (i) tipo de complexo verbal - controle de cada forma (semi)-auxiliar que se associa ao verbo principal; (ii) elemento interveniente no complexo verbal - observação de construções que contêm preposições ou advérbios entre as formas verbais; (iii) tipo de clítico - presença de $m e$, te, se (indeterminador/ apassivador; reflexivo/ inerente), o, lhe, nos, vos -; (iv) contexto antecedente ao complexo verbal - controle da presença de elementos supostamente proclisadores e não proclisadores; e (v) forma do verbo auxiliar - observação do tempo/modo da primeira forma verbal do complexo.

O quadro 1 sintetiza o comportamento dos dados da variante mais produtiva, a intra-CV sem hífen, em relação aos grupos de fatores linguísticos.

A sistematização dos resultados no quadro 1 permite observar que contextos variados acolhem o pronome átono sem hífen no interior do complexo verbal, de modo que não se detecta, com nitidez, motivação específica para essa variante. A seguir, detalha-se o comportamento dos dados quanto a essas variáveis. 
Em relação ao tipo de complexo, a presença do pronome sem hífen entre as formas verbais deu-se em diversas construções registradas no corpus. Dentre elas, foi possível observar, apenas, maior uso da variante nas estruturas formadas por vir/ir e ter de/que.

\begin{tabular}{||c|c|}
\hline \multicolumn{2}{||c|}{ Contextos da variante intra-CV sem hífen em complexos verbais com infinitivo } \\
\hline Variáveis & Contextos de utilização \\
\hline Tipo de complexo verbal & Todas as construçôes \\
\hline $\begin{array}{c}\text { Elemento interveniente no } \\
\text { complexo verbal }\end{array}$ & Complexos com ou sem elemento interveniente \\
\hline Tipo de clítico & Pronomes $m e / t e / n o s$, se reflexivo/inerente \\
\hline $\begin{array}{c}\text { Contexto antecedente ao } \\
\text { complexo verbal }\end{array}$ & Elementos proclisadores e não proclisadores \\
\hline Tempo e modo do auxiliar & Formas de diversos tempos e modos \\
\hline \hline
\end{tabular}

Quadro 1 - Sistematização dos contextos de maior ocorrência da variante intra-CV sem hífen (pode me dizer) em função de variáveis linguísticas controladas em Peterson (2010).

Com relação à variável ausência/presença de elemento interveniente no complexo verbal, salienta-se que, embora se registre a variante intra-CV sem hífen em construções com ou sem elemento interveniente, a presença de elementos (como em tem que se dizer) faz com que se concretize a variante de forma ainda mais expressiva.

No que toca ao tipo de clítico, merece destaque a atuação desse grupo de fatores quanto à concretização da variante intra-CV sem hífen. De modo geral, as formas pronominais que registram essa forma alternante são argumentos do segundo verbo. Os pronomes de $1^{\mathrm{a}}$ e $2^{\mathrm{a}}$ pessoa ocorreram em $100 \%$ dos dados na posição intra-CV sem hífen e o pronome se reflexivo/inerente em $89 \%$, o que pode ser indicativo de que essa seja a posição não-marcada para esses pronomes, independentemente da atuação de outros condicionamentos. Houve, ainda, uma única ocorrência do pronome the e uma do se indeterminador.

No que concerne à variável contexto antecedente ao complexo, os resultados oferecem evidências de que não se confirma a atuação de elementos supostamente proclisadores. Verificou-se que, no corpus, a presença do sujeito no contexto anterior ao complexo - fator que não é considerado tradicional 'atrator' do pronome foi o que apresentou maior percentual do clítico $(80 \%)$ entre as duas formas verbais. Além disso, registrouse em contexto com elemento subordinativo, apontado pela tradição gramatical como proclisador canônico, percentual maior do clítico sem hífen no interior da construção verbal do que antes dela, o que comprova, mais uma vez, a preferência pela variante interna ao complexo e sem hífen nas cartas brasileiras, independentemente da chamada "atração" gramatical.

Quanto ao tempo e modo da forma verbal auxiliar, observou-se que, com exceção do verbo auxiliar no gerúndio, todas as outras formas verbais acomodam o clítico na posição intra-CV sem hífen.

De todas as variáveis ora comentadas, percebe-se apenas na que se refere ao tipo de clítico um contexto preferencial para a variante $\mathrm{V} 1 \mathrm{cl} \mathrm{V} 2$. Em outras palavras, essa variante comportou-se como a ordem não marcada, natural, em praticamente todos os contextos controlados, mas preferencialmente com os clíticos argumentais $-1^{a}$ e $2^{a}$ pessoas e se reflexivo/inerente -, ligados sintaticamente à forma verbal não-finita.

Desse modo, a representação dessa variante pode ser sintetizada da seguinte forma:

\section{$(\mathrm{X})+\mathrm{V} 1+(\mathrm{X})+$ me/te/nos/se reflexivo/inerente $+\mathrm{V} 2$ infinitivo \\ [(o menino) pode me dizer; (ele) tem que se encontrar para ser feliz.]}

A fim de sistematizar os contextos em que se realizou o clítico na posição anterior ao complexo verbal, segunda forma alternante mais frequente na amostra analisada (21 dados), apresentam-se, no quadro 2, os contextos linguísticos que registraram maiores índices percentuais da variante.

Tendo em vista a sistematização dos resultados no quadro 2, podem-se observar os contextos específicos que registraram o pronome átono antes do complexo verbal, de acordo com algumas motivações de natureza estrutural. 
No que se refere ao tipo de complexo verbal, salienta-se que a construção formada pelo auxiliar modal poder foi o único que apresentou percentual considerável na posição pré-CV (40\%). Ademais, verificou-se que todas as ocorrências da variante pré-CV com esse tipo de complexo foram antecedidas de possível elemento proclisador.

O controle da variável "ausência/presença de elemento interveniente no complexo verbal" demonstrou que, em complexos com elemento interveniente, o clítico não apareceu na posição pré-CV. Ao que parece, esse contexto desfavorece, de fato, a chamada "subida do clítico".

\begin{tabular}{|c|c|}
\hline \multicolumn{2}{|c|}{ Contextos da variante pré-CV em complexos verbais com infinitivo } \\
\hline Variáveis & Contextos de utilização \\
\hline Tipo de complexo verbal & Poder + infinitivo \\
\hline $\begin{array}{c}\text { Elemento interveniente no } \\
\text { complexo verbal }\end{array}$ & Complexos sem elemento interveniente \\
\hline Tipo de clítico & Se indeterminador /apassivador \\
\hline $\begin{array}{c}\text { Contexto antecedente ao complexo } \\
\text { verbal }\end{array}$ & $\begin{array}{c}\text { Partícula de negação, elemento subordinativo e } \\
\text { advérbio (1 ocorrência) }\end{array}$ \\
\hline Tempo e modo do auxiliar & Tempos do modo indicativo \\
\hline
\end{tabular}

Quadro 2 - Sistematização dos contextos de maior ocorrência da variante pré-CV (me pode dizer) em função de variáveis linguísticas controladas em Peterson (2010).

No tocante ao tipo de clítico, observou-se que o se indeterminador/ apassivador foi a única forma pronominal que ocorreu na posição pré-CV. De 28 ocorrências desse pronome, 21 foram realizadas nessa posição, totalizando $75 \%$ das ocorrências.

No que se refere à variável contexto antecedente ao complexo, ocorreu a variante pré-CV (com se indeterminador/apassivador) primordialmente quando a construção verbal se encontra antecedida de partícula de negação e de elemento subordinativo. Do que se expôs até aqui, pode-se concluir que a atuação dos chamados elementos "atratores" não se dá de forma geral nos complexos com infinitivos, mas fica restrita aos contextos ora sintetizados, que se referem ao tipo de clítico e ao tipo de complexo verbal. Não se pode descartar a hipótese de que a presença desse elemento nas construções com a variante pré-CV esteja relacionada a um condicionamento de natureza fonético-fonológica, como alguns estudos buscam evidenciar (cf. VIEIRA, 2002).

Por fim, com relação à variável tempo e modo da forma auxiliar, verificou-se que a variante pré-CV ocorreu apenas com os tempos do modo indicativo, que foram os mais produtivos no corpus.

Reunindo-se o comportamento de todas as variáveis, uma construção prototípica do uso da variante pré-CV no corpus pode ser ilustrada pela seguinte estrutura:

\section{Elemento proclisador $+s e$ indeterminador/apassivador $+\mathrm{V} 1+\mathrm{V} 2$ infinitivo [Não/que se pode imaginar X/ não se pode assistir a X.]}

Com o propósito de demonstrar os contextos preferenciais da variante pós-complexo verbal (20 dados), nos dados com infinitivo, apresenta-se, a seguir, o quadro 3.

Primeiramente, merece destaque que, de todas as variáveis apresentadas no quadro acima, não se pôde delinear contexto de maior especificidade em cada grupo, exceto no que se relaciona ao tipo de clítico. $\mathrm{O}$ pronome acusativo de terceira pessoa foi o único fator que exibiu $100 \%$ de ocorrências na variante póscomplexo verbal, sugerindo ser altamente favorecedor dessa posição nos complexos com infinitivo. Além desse pronome, a variante V1 V2-cl foi registrada ainda com o se reflexivo/ inerente, clítico que é usualmente argumento do verbo principal.

O contexto prototípico de uso dessa variante poderia ser representado, então, pela seguinte construção: 
$(\mathrm{X})+\mathrm{V} 1+$ infinitivo $+\mathbf{o}, \mathbf{a}(\mathrm{s}) /$ se reflexivo/inerente

[(alguém) pode fechá-lo; (alguém) poderia dirigir-se ao balcão.]

\begin{tabular}{|c|c|}
\hline \multicolumn{2}{|c|}{ Contextos da variante pós-CV em complexos verbais com infinitivo } \\
\hline Variáveis & Contextos de utilização \\
\hline Tipo de complexo verbal & Construções diversas \\
\hline $\begin{array}{l}\text { Elemento interveniente no } \\
\text { complexo verbal }\end{array}$ & Complexos com ou sem elemento interveniente \\
\hline Tipo de clítico & $\begin{array}{l}\text { Pronome acusativo de terceira pessoa }(16 / 16) \mathrm{e} \\
\text { se reflexivo/inerente }(4 / 36) \text {, preferencialmente }\end{array}$ \\
\hline $\begin{array}{c}\text { Contexto antecedente ao complexo } \\
\text { verbal }\end{array}$ & Elementos proclisadores e não proclisadores \\
\hline Tempo e modo do verbo auxiliar & Formas de diversos tempos e modos \\
\hline
\end{tabular}

Quadro 3 - Sistematização dos contextos de maior ocorrência da variante pós-CV (pode dizer-me) em função de variáveis linguísticas controladas em Peterson (2010).

Apesar de o corpus ter oferecido apenas seis ocorrências da variante intra-complexo verbal com hífen - o que torna pouco produtiva a apresentação de um quadro com sistematização -, podem ser feitas algumas observações. Quanto aos tipos de complexo, verificou-se uma distribuição das ocorrências por poder (dois dados), dever (dois dados), procurar/resolver (um dado cada). Das seis ocorrências, cinco foram realizadas em construções sem a presença de elemento interveniente no complexo verbal. Em relação ao tipo de clítico, todos eram do tipo se indeterminador/ apassivador. Concernente ao possível elemento proclisador, chama à atenção que quatro das seis ocorrências estavam em contexto de início absoluto de oração, contexto tradicionalmente assinalado como indutor da ênclise. Por fim, no que se refere ao tempo e modo da forma verbal auxiliar, este estava primordialmente no tempo presente do indicativo. Assim, acredita-se que todos esses contextos juntos propiciem a realização da variante intra-CV com hífen.

Uma construção ilustrativa da variante intra-CV no corpus seria, então, a seguinte:

\section{$\mathbf{V 1}+$ se indeterminador/ apassivador + V2}

[Pode-se/deve-se imaginar X/Pode-se/deve-se assistir a X.]

Feitas as sistematizações acerca de cada variante da ordem dos clíticos em complexos verbais com infinitivo em relação aos grupos de fatores linguísticos, sintetiza-se, na tabela 2 e no gráfico 1 , a seguir, o comportamento do fenômeno em relação à variável extralinguística tipo de jornal.

Tabela 2 - Distribuição dos dados da ordem dos clíticos pronominais em complexos verbais com verbo principal no infinitivo - geral e por veículo jornalístico (PETERSON, 2010):

\begin{tabular}{|c|c|c|c|c|c|}
\hline Jornal & $\mathrm{cl} \mathrm{V1} \mathrm{V2}$ & $\mathrm{V} 1-\mathrm{cl} \mathrm{V} 2$ & $\mathrm{~V} 1 \mathrm{cl} \mathrm{V} 2$ & $\mathrm{~V} 1 \mathrm{~V} 2-\mathrm{cl}$ & Total \\
\hline O Globo & $17-23 \%$ & $4-5 \%$ & $37-50 \%$ & $16-22 \%$ & 74 \\
\hline Extra & $4-15 \%$ & $2-8 \%$ & $17-65 \%$ & $3-12 \%$ & 26 \\
\hline Meia Hora & - & - & $2-67 \%$ & $1-33 \%$ & 3 \\
\hline Total & $21-21 \%$ & $6-6 \%$ & $56-54 \%$ & $20-19 \%$ & 103 \\
\hline
\end{tabular}

No que tange ao tipo de jornal, ressalta-se, aqui, o comportamento particular do jornal Meia Hora, que praticamente não se vale do uso de clíticos pronominais em complexos com infinitivo, tendo apresentado apenas três ocorrências.

O jornal Extra corrobora, quanto ao número de clíticos pronominais, a suposta localização em posição intermediária entre $O$ Globo e o Meia Hora, exibindo, somente, 26 dados de clíticos, sendo 17 na posição intra-CV sem hífen. Ainda em relação ao jornal Extra, verifica-se que esse veículo apresenta o clítico na posição intra-CV sem hífen em maior percentual (65\%) do que o jornal $O$ Globo (50\%), o que pode indicar, ainda que sensivelmente, que este utilize com menos liberdade a variante já atestada como preferida em estudos diversos do PB oral (cf. VIEIRA, 2002). 
O jornal $O$ Globo foi o que mais apresentou clíticos em complexos verbais (74 dados) e, também, foi o que mais exibiu os pronomes átonos na posição pré-CV, todos em contextos previstos tradicionalmente como implementadores da próclise, aproximando-se, assim, nesse aspecto, do comportamento recomendado em manuais gramaticais.

Chama à atenção, ainda, o fato de que, das 20 ocorrências do clítico na posição pós-CV, 16 pertençam ao jornal $O$ Globo. Ao que parece, esse veículo de comunicação também se destaca dos demais no que se refere à maior produtividade da variante pós-verbal.

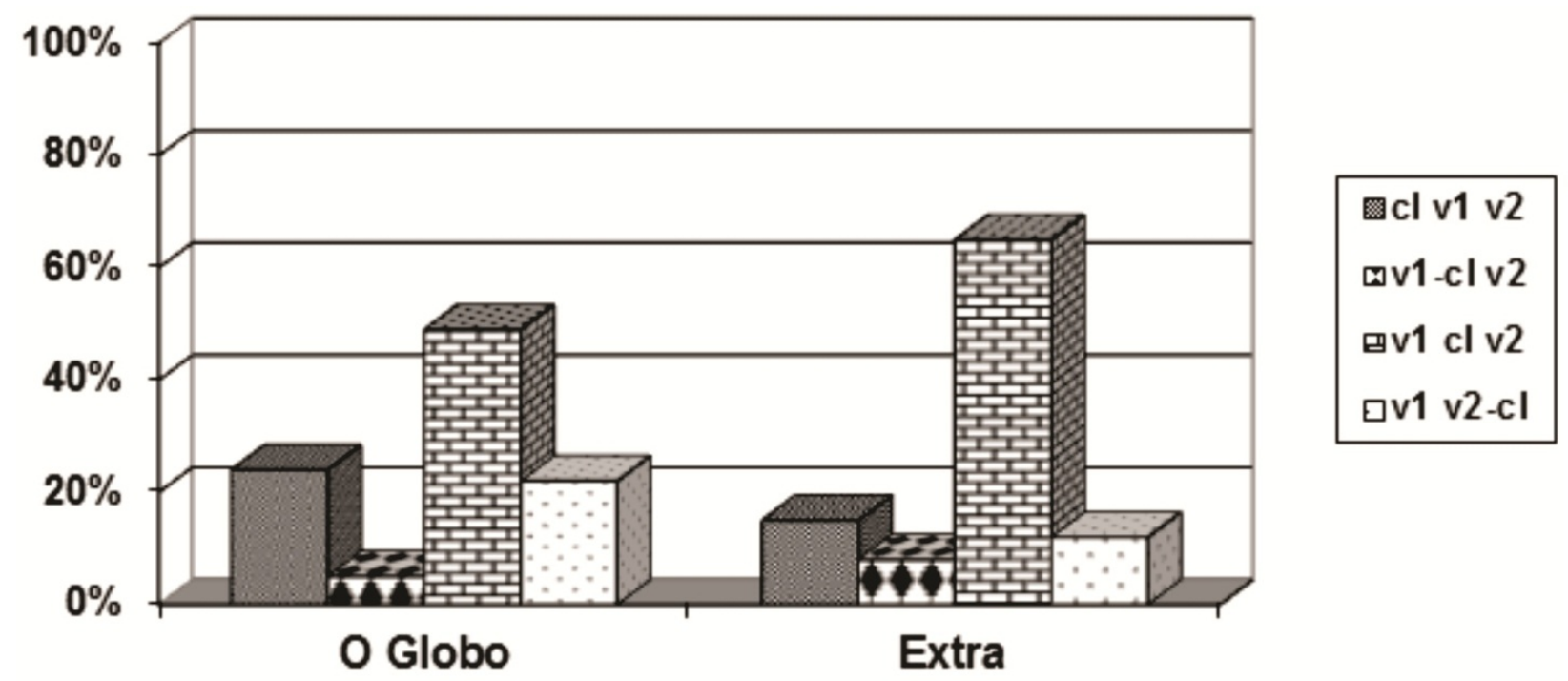

Gráfico 1 - Distribuição dos dados da ordem dos clíticos pronominais em complexos verbais com verbo principal no infinitivo por veículo jornalístico (PETERSON, 2010).

Com base nos resultados referentes ao tipo de jornal, ora sistematizados, e também nas características gerais que o contato com os três veículos de comunicação faz perceber, verificam-se evidências que sustentam a proposta de um continuum no perfil dos jornais, e por consequência no dos textos, relacionado tanto às normas linguísticas praticadas, quanto ao registro/estilo, continuum que vai do mais culto e formal ao mais popular e informal ${ }^{3}$. Esse continuum pode ser esquematizado da seguinte forma:

[+ diversidade de temas]

[+ diversidade de gêneros textuais]

[+ espírito reflexivo/avaliativo]

[+ variedade culta]

[+ registro formal]
[- diversidade de temas]

[- diversidade de gêneros textuais]

[- espírito reflexivo/avaliativo]

[- variedade culta]

[- registro formal]

\section{O Globo Extra}

Meia Hora

Figura 1 - Continuum proposto em Peterson (2010) em relação ao perfil dos jornais analisados.

\section{CONSIDERAÇÕES FINAIS}

Após a apresentação dos resultados da ordem dos clíticos pronominais em complexos verbais, pode-se sintetizar o padrão de colocação pronominal verificado nas cartas de leitor, em função das motivações linguísticas e extralinguísticas controladas, consoante o primeiro objetivo da investigação.

No que se refere à posição dos clíticos em complexos verbais, tanto as cartas do jornal $O$ Globo, como as dos jornais Extra e Meia Hora confirmaram, embora com percentuais distintos, a maior produtividade da variante intra-CV sem hífen, variante que corresponderia ao que os estudos mostram ser a opção

\footnotetext{
${ }^{3}$ Segundo Bortoni-Ricardo (2005, p. 40), a variação pode ser compreendida segundo três continua fundamentais - urbanização, oralidade-letramento e monitoração estilística -, os quais permitiriam apreender de forma mais precisa a complexa situação sociolinguística do Português do Brasil.
} 
preferencial do PB vernacular, concebido, consoante Labov (1972), como aquele que apresenta as formas privilegiadas em situações de fala espontânea: a próclise a V2, forma verbal não-finita. Independentemente da presença de contextos que tendem a favorecer a posição pré-CV, foi realizada, na maior parte dos casos, a variante intra-CV sem hífen (pode me dizer).

Em relação aos dados de complexos verbais participiais, merece destaque que a tendência à realização da variante intra-CV sem hífen se altera em contexto de construção passiva analítica, passando a prevalecer a posição pré-CV (não lhe foi informado).

Nas estruturas formadas por gerúndio como verbo principal (em sua maioria com o verbo estar), o clítico tende a aparecer no interior do complexo verbal, independentemente do tipo de clítico ou da presença de possível elemento desencadeador de próclise.

No tocante aos dados de clíticos em estruturas formadas por verbo principal no infinitivo, a análise permitiu indicar não só a maior expressividade da variante intra-CV sem hífen, como também os contextos favorecedores da realização do clítico nessa e nas outras variantes. Atuam, em especial, nos dados da posição intra-CV sem hífen, os clíticos de $1^{\mathrm{a}} / 2^{\mathrm{a}}$ pessoas e o se reflexivo/inerente, normalmente argumentos da forma infinitiva. A hifenização do clítico à primeira forma verbal foi pouco produtiva no corpus e, ao que parece, está fortemente relacionada ao contexto de construção verbal modal com o pronome se indeterminador/ apassivador em início absoluto de oração (pode-se assistir a). A variante pré-CV ocorre preferencialmente em construções modais com o se indeterminador/apassivador antecedida de elemento proclisador (não se pode assistir a) e a variante pós-CV fica circunscrita praticamente ao pronome acusativo de $3^{\mathrm{a}}$ pessoa - o, a, os, as (pode encontrá-lo).

Embora ultrapasse o escopo do presente artigo, é oportuno avaliar o caráter efetivamente variável da totalidade dos dados submetidos à análise. Da sistematização proposta no presente artigo, é possível demonstrar que a ordem dos clíticos pronominais é distinta quanto à forma do verbo principal, o que particulariza o comportamento do fenômeno nas construções participiais, gerundivas e infinitivas, que devem ser analisadas separadamente. No que se refere às infinitivas, em particular, algumas das supostas formas alternantes de colocação não se encontram efetivamente em variação com todas as demais. Pode-se observar que a alternância da ordem, ao menos de determinadas formas pronominais, se dá, na maior parte dos dados coletados na escrita jornalística das cartas de leitores, em pares: antes ou depois de V1, no caso do se indeterminador/ apassivador; antes ou depois de V2, no caso do se reflexivo/ inerente. O clítico acusativo de $3^{\mathrm{a}}$ pessoa aparece categoricamente depois de V2 infinitivo. Ao que parece, maior possibilidade de variação na escrita se encontra com os demais clíticos.

No que se refere ao objetivo de verificar se há um padrão típico de colocação pronominal no gênero carta de leitor, o estudo revela, primeiramente, que há diferenças expressivas nos textos consoante o veículo de comunicação em que as cartas foram publicadas. Apesar disso, deve-se registrar que, nos três jornais, a variante interpretada como próclise ao verbo principal foi a mais produtiva, o que pode, por hipótese, ser uma possível influência do gênero em questão, que permite registrar, com maior ou menor produtividade, construções consideradas vernaculares.

Avaliando a proximidade/ distância das normas concretizadas nas cartas em relação às normas idealizadas em compêndios gramaticais prescritivos, verificou-se que tal distanciamento se mostra, numa gradação, discreto em $O$ Globo, um pouco expressivo no Extra, e muito expressivo no Meia Hora. Em linhas gerais, $O$ Globo tende a valer-se de estruturas mais próximas (ainda que não categóricas) do que propõe a prescrição gramatical; o Meia Hora, estruturas mais distantes; e o Extra localiza-se, quanto a essa tendência, entre os dois veículos. Confirmou-se, assim, o continuum proposto para os jornais, no que tange à ordem dos clíticos pronominais. Em função desse continuum, pode-se postular maior ou menor teor de variação do fenômeno, pressupondo que as estruturas mais distantes do vernáculo brasileiro se manifestem em veículos como $O$ Globo, em que se registram estruturas pré-CV, intra-CV com hífen, e pós-CV em maior número de contextos.

Espera-se, por fim, que estudos referentes aos usos da escrita monitorada em diferentes gêneros textuais e veículos, considerando diversos fenômenos gramaticais, colaborem para a compreensão da pluralidade de normas que caracterizam o que se convencionou considerar "padrão culto escrito". Os resultados relativos à colocação pronominal ora apresentados permitem atestar que esse suposto padrão constitui, sem dúvida, 
muito mais uma abstração teórica, uma norma subjetiva idealizada como uniforme, bastante distante das heterogêneas normas objetivas das escritas praticadas por usuários do Português em veículos que, em maior ou menor grau, têm compromisso em divulgar usos linguísticos supostamente "cultos".

\section{REFERÊNCIAS}

CUNHA, Celso; CINTRA, Lindley. Nova gramática do português contemporâneo. 3. ed. Rio de Janeiro: Nova Fronteira, 2001.

FISCHER, John L. Social influences on the choice of a linguistic variant. Word, n. 14, p. 47-56, 1958.

LABOV, William. Sociolinguistic patterns. Philadelphia: University of Pennsylvania Press, 1972. Principles of linguistic change. Cambridge: Blackwell, 1994.

PETERSON, Márcia Saldanha. A ordem dos clíticos pronominais em lexias verbais simples e complexas em cartas de leitor: uma contribuição da sociolinguística variacionista. Dissertação (de Mestrado Linguística) - UFRJ, Faculdade de Letras, Rio de Janeiro, 2010.

VIEIRA, Silvia Rodrigues. Colocação pronominal nas variedades européia, brasileira e moçambicana: para a definição da natureza do clítico em Português. Tese (de Doutorado em Linguística) - UFRJ, Faculdade de Letras, Rio de Janeiro, 2002.

WEINREICH, Uriel; LABOV, William; HERZOG, Marvin I. Fundamentos empíricos para uma teoria da mudança linguística. Tradução de Marcos Bagno; revisão técnica de Carlos Alberto Faraco; posfácio de Maria da Conceição A. de Paiva, Maria Eugênia Lamoglia Duarte. São Paulo: Parábola Editorial, 2006. [1968].

Recebido em 16/01/12. Aprovado em 23/04/12. 